\title{
GRAND-4: the German retrospective analysis of long-term persistence in women with osteoporosis treated with bisphosphonates or denosumab
}

\author{
P. Hadji ${ }^{1}$ - I. Kyvernitakis ${ }^{2}$ - P. H. Kann ${ }^{3}$ - C. Niedhart ${ }^{4}$ - L. C. Hofbauer ${ }^{5}$. \\ H. Schwarz ${ }^{6}$ - A. A. Kurth ${ }^{7}$. F. Thomasius ${ }^{8}$ - M. Schulte ${ }^{9}$ M. Intorcia ${ }^{10}$. \\ E. Psachoulia ${ }^{10}$ T. Schmid ${ }^{9}$
}

Received: 18 February 2016 / Accepted: 28 April 2016/Published online: 12 May 2016

(C) The Author(s) 2016. This article is published with open access at Springerlink.com

\begin{abstract}
Summary This retrospective database study assessed 2-year persistence with bisphosphonates or denosumab in a large German cohort of women with a first-time prescription for osteoporosis treatment. Compared with intravenous or oral bisphosphonates, 2-year persistence was 1.5-2 times higher and risk of discontinuation was significantly lower $(P<0.0001)$ with denosumab. Introduction Persistence with osteoporosis therapies is critical for fracture risk reduction. Detailed data on long-term persistence $(\geq 2$ years) with bisphosphonates and denosumab are sparse.
\end{abstract}

P. Hadji

hadji.peyman@khnw.de

1 Department of Bone Oncology, Endocrinology, and Reproductive Medicine, Krankenhaus Nordwest, Steinbacher Hohl 2-26, 60488 Frankfurt am Main, Germany

2 Department of Bone Oncology, Gynecological Endocrinology and Reproductive Medicine, Nordwest Hospital, Frankfurt am Main, Germany

3 Centre for Internal Medicine - Endocrinology \& Diabetes, Philipps University of Marburg, Marburg, Germany

4 Gemeinschaftspraxis, Heinsberg, Germany

5 Division of Endocrinology, Diabetes, and Bone Diseases, Department of Medicine 3 and Center for Healthy Aging, TU Dresden Medical Center, Dresden, Germany

6 Facharztpraxis für Orthopädie und Physiotherapie, Freudenstadt, Germany

7 Themistocles Gluck Hospital, Ratingen, Germany

8 Department of Bone Oncology and Osteoporosis Center, Krankenhaus Nordwest, Frankfurt am Main, Germany

9 Amgen (Europe) GmbH, Munich, Germany

10 Amgen Europe, Zug, Switzerland
Methods From the German IMS ${ }^{\circledR}$ database, we included women aged 40 years or older with a first-time prescription for bisphosphonates or denosumab between July 2010 and August 2014; patients were followed up until December 2014. The main outcome was treatment discontinuation, with a 60-day permissible gap between filled prescriptions. Two-year persistence was estimated using Kaplan-Meier survival curves, with treatment discontinuation as the failure event. Denosumab was compared with intravenous (i.v.) and oral bisphosphonates separately. Cox proportional hazard ratios (HRs) for the 2-year risk of discontinuation were calculated, with adjustment for age, physician specialty, health insurance status, and previous medication use.

Results Two-year persistence with denosumab was significantly higher than with i.v. or oral bisphosphonates $(39.8 \%[n=21,154]$ vs $20.9 \%$ [i.v. ibandronate; $n=20$, 472] and $24.8 \%$ [i.v. zoledronic acid; $n=3966$ ] and $16.7-$ $17.5 \%$ [oral bisphosphonates; $n=114,401$ ]; all $P<0.001$ ). Patients receiving i.v. ibandronate, i.v. zoledronic acid, or oral bisphosphonates had a significantly increased risk of treatment discontinuation than did those receiving denosumab $(\mathrm{HR}=1.65,1.28$, and 1.96-2.02, respectively; all $P<0.0001)$.

Conclusions Two-year persistence with denosumab was 1.5-2 times higher than with i.v. or oral bisphosphonates, and risk of discontinuation was significantly lower with denosumab than with bisphosphonates. A more detailed understanding of factors affecting medication-taking behavior may improve persistence and thereby reduce rates of fracture.

Keywords Bisphosphonates - Compliance - Denosumab · Osteoporosis · Persistence 


\section{Introduction}

Osteoporosis is recognized worldwide as an important health condition because of its high prevalence and detrimental consequences, such as increased risk of fractures. It is characterized by extensive loss of bone mass due to structural deterioration of bone, which leads to increasing frailty $[1,2]$. The most recent report on the prevalence of osteoporosis among 1.7 million individuals registered on a health insurance database in Germany found that the condition affects approximately $14 \%$ of the overall population above the age of 50 years and approximately $24 \%$ of women in this age group [3].

Several osteoporosis treatments are available that have been found to be effective in randomized controlled trials (RCTs). Bisphosphonates, which were introduced as an antiresorptive therapy in the mid-1990s, suppress osteoclast activity, thereby reducing bone turnover and increasing bone mineral density. In turn, this significantly reduces fracture rate [4]. However, depending on concomitant disease and medications, oral bisphosphonates may be associated with poor absorption and gastrointestinal adverse events [5]. Intravenous (i.v.) bisphosphonates became available a decade later, offering a new mode of administration. More recently, subcutaneous (s.c.) denosumab was approved for the treatment of men and postmenopausal women at increased risk of fracture [6]. Denosumab is a fully human monoclonal antibody with affinity and specificity for RANK ligand (RANKL) [7], a primary mediator of osteoclast activity and differentiation [8].

The chronic nature of osteoporosis means that long-term treatment is required. This can, however, lead to poor persistence and compliance with medication, both of which increase fracture risk [9-14]. In two large retrospective cohort analyses on compliance and persistence and the associated risk of fractures, which included more than 4000 women receiving various oral bisphosphonates (GRAND) [9] and 296,300 Hungarian women receiving osteoporosis therapies administered orally or parenterally [15], 2-year persistence with treatment was only 12.9 and $16 \%$, respectively. These studies showed that both compliance and persistence with treatment had a significant impact on fracture risk; hence, the persistence rates reported in these studies appear inadequate. Similar analyses of persistence with i.v. bisphosphonates in Germany showed moderate 12 -month persistence rates of $65.6 \%$ for zoledronic acid $5 \mathrm{mg}$ i.v. (administered every 12 months) and $56.6 \%$ for ibandronate $3 \mathrm{mg}$ i.v. (administered every 3 months) [16], and the literature analysis performed as part of the Swedish Adherence Register Analysis (SARA) study found that 2-year persistence with oral bisphosphonates reported in studies from around the world ranged from 16 to $46 \%$ [17].

In contrast to these findings, in a prospective, noninterventional study of women with postmenopausal osteoporosis [18] conducted in North America, 12-month persistence with 6-monthly denosumab was $82 \%$. Interestingly, patients with the highest persistence rates were those with exposure to other osteoporosis treatments before enrollment (83\% for those with previous exposure vs $74 \%$ for those without), which may indicate that switching from other osteoporosis treatments (e.g., bisphosphonates) to denosumab can improve treatment persistence [18]. Similar 12-month persistence rates with denosumab of 70-95.5\% were reported in a European observational study of 1500 women with postmenopausal osteoporosis, the SARA study of 2315 women with postmenopausal osteoporosis, a retrospective German cohort analysis of 6159 denosumab-naïve women with osteoporosis, and the Hungarian study noted above [15, 17, 19, 20]. Furthermore, the improvement in persistence following a medication switch may be greater when patients switch to denosumab than to another bisphosphonate: a pooled analysis of data from two international, randomized, open-label studies found that women with poor adherence to daily or weekly oral bisphosphonates reported better treatment satisfaction when switching to denosumab than when switching to monthly oral bisphosphonates [21]. These findings are very promising; however, data on persistence rates for i.v. bisphosphonates and denosumab over a 2-year period are sparse. It is also still not clear which factors are associated with poor persistence.

The aim of this study was to evaluate long-term persistence with different osteoporosis treatments in a large sample of women receiving oral or i.v. bisphosphonates, or s.c. denosumab in a real-world setting in Germany, and to identify factors associated with discontinuation of osteoporosis therapy.

\section{Methods}

\section{Database}

This study used the IMS $®$ Longitudinal Rx (LRx) database, which includes data from pharmacy centers nationwide and is used to process prescription data for all German patients within statutory health insurance programs for reimbursement purposes. Data entries comprise patient-specific information, such as anonymized identification number, age, sex, insurance company, and area of residence, as well as prescription information, including the prescriber's anonymized identification number, prescription date, and pack size. The IMS LRx database holds details of about $60 \%$ of prescriptions issued in Germany [22].

\section{Study population}

Women were included who had received a first-time prescription for bisphosphonates (oral or i.v.) or denosumab (s.c. once every 6 months) between July 2010 and a cutoff date of 
August 2013 for i.v. zoledronic acid once yearly, February 2014 for denosumab and oral bisphosphonates (alendronate $70 \mathrm{mg}$ or risedronate $35 \mathrm{mg}$ once weekly, ibandronate $150 \mathrm{mg}$ once monthly), or May 2014 for i.v. ibandronate once every 3 months. These follow-up dates were determined according to drug administration frequency: the minimum follow-up period was 16 months for zoledronic acid, 10 months for denosumab, and 7 months for i.v. ibandronate. The date of first prescription was defined as the index event, with follow-up until December 2014 at the latest.

Further inclusion criteria were age 40 years or older at the index event and the availability of data for at least 365 days before the index date (necessary for valid identification of treatment initiation).

Patients with a history of any prescription for antineoplastic agents (Anatomical Therapeutic Chemical [ATC] class: L1), cytostatic hormones (ATC class: L2), or any oncological treatment documented within the 12-month period preceding the index date were excluded.

\section{Study outcomes}

The main outcome was treatment discontinuation in the 2 years after the index date. Treatment discontinuation was defined as a gap of more than 60 days without filling a new prescription after the expected refill date during the observation period. Patients restarting their initial treatment or starting another drug after a gap ("grace period") of 60 days had elapsed were classified as non-persistent, as were those who discontinued their initial therapy and received no further treatment. Patients who discontinued their original therapy and started another drug within 60 days were included in the drug cohort for which they maintained the longest duration of persistence. Sensitivity analyses were performed with grace periods of 30, 90, and 120 days. Persistence was calculated using the discontinuation data.

A longitudinal dataset of medication supply was built for each patient, and non-persistence with each treatment (denosumab, i.v. ibandronate, i.v. zoledronic acid, oral alendronate, oral ibandronate, and oral risedronate) was calculated. To build these longitudinal databases, the number of days of drug supply was calculated from quantity and dosage information associated with each prescription record. All patients were followed up for a minimum of the respective number of days of drug supply plus 60 days and a maximum of up to 2 years from their index date, to identify therapy discontinuation.

\section{Covariates}

Previous treatments (prescriptions in the 12-month period before the index date) were categorized based on ATC classifications and included calcium (ATC class: A12A), vitamin D (ATC class: A11C2 or A11C3), hormone therapy (ATC class: G03), and pain medication (ATC class: N02 or M01A). Previous treatment also included oral bisphosphonates (ATC class: M05B3); this particular category was included as a covariate in the analyses of i.v. bisphosphonates and denosumab. Demographic data included age, health insurance type (general regional funds [AOKs, Barmer GEK, TK, DAK], company-based funds [BKKs], guild-based funds [IKKs] or other funds), and specialty of the physician who initiated bisphosphonate therapy (orthopedic surgeon, internist, or other).

\section{Statistical analysis}

Kaplan-Meier survival curves were used to estimate 2-year persistence rates, with treatment discontinuation as the failure event. Two comparisons were made: denosumab versus i.v. bisphosphonates and denosumab versus oral bisphosphonates. The bisphosphonate data were pooled for each of these comparisons. Patients were censored at the time they were lost to follow-up or when they discontinued treatment, whichever occurred first. Covariates associated with treatment discontinuation were assessed using a Cox proportional hazards regression model, with a stepwise selection procedure and an entry criterion of $P=0.1$ used to determine the final model. Cox regression analyses were performed separately for comparisons of denosumab with i.v. bisphosphonates and denosumab with oral bisphosphonates. Hazard ratios (HRs) for the 2-year risk of therapy discontinuation were adjusted for age, physician specialty, health insurance status of the patient, and previous medication use.

The proportional hazards assumption was assessed and upheld for all analyses. Two-sided tests were used, and a $P$ value of 0.05 was considered statistically significant. All analyses were carried out using SAS 9.3 (SAS Institute, Cary, NC, USA).

\section{Results}

\section{Characteristics of study patients}

Our analysis included 21,154 women treated with denosumab, 20,472 receiving i.v. ibandronate, 3966 receiving i.v. zoledronic acid, 90,077 receiving oral alendronate, 6235 receiving oral ibandronate, and 18,089 receiving oral risedronate.

Baseline patient characteristics are summarized by treatment in Tables 1 and 2. Patients treated with denosumab were significantly older than those treated with oral or i.v. bisphosphonates (both $P<0.001$ ) (Tables 1 and 2). Additionally, compared with patients receiving i.v. or oral bisphosphonates, patients receiving 
denosumab were more likely to be treated by orthopedic surgeons and were less likely to be treated by internists (both $P<0.001$ ). A significantly higher proportion of patients receiving denosumab had used oral bisphosphonates, calcium, vitamin $\mathrm{D}$, and hormone therapy in the 12 months before the index date than had individuals in the oral and i.v. bisphosphonate groups (both $P<0.001$ ) (Tables 1 and 2). More than half $(52.4 \%)$ of patients in the denosumab group had received oral bisphosphonates at any time before initiating denosumab, and $16.9 \%$ had previously received an i.v. bisphosphonate (data not shown).

\section{Kaplan-Meier survival analyses}

At 12 months, persistence with therapy was higher in the denosumab group than in the i.v. ibandronate or i.v. zoledronic acid groups (55.9 vs 42.9 and $33.8 \%$, respectively). At 2 years of follow-up, persistence with denosumab remained higher than in the i.v. ibandronate or i.v. zoledronic acid groups (39.8 vs 24.8 and $20.9 \%$; Table 3) A comparison of denosumab with the pooled i.v. bisphosphonate data showed that the difference in persistence was highly significant $(P<0.001$; Fig. 1a). Persistence was also found to be higher with denosumab than with i.v. bisphosphonates in the sensitivity analyses, which used grace periods of 30,90 , and 120 days (Table 3 ).

At 12 months, persistence with denosumab was also higher than with oral bisphosphonates (55.9 vs approximately $30 \%$ ), with sensitivity analyses using grace periods of 30, 90, and 120 days showing similar results (Table 3). At 2 years of follow-up, the differences in persistence were maintained, with a higher proportion of persistent patients in the denosumab group than in the oral bisphosphonate groups (39.8 vs 16.7-17.5\%). A comparison of denosumab with the pooled oral bisphosphonate data showed that this difference was highly significant $(P<0.001$; Fig. 1b). The difference in persistence between
Table 1 Baseline characteristics of study patients: denosumab versus intravenous bisphosphonates

\begin{tabular}{|c|c|c|c|c|}
\hline Variable & $\begin{array}{l}\text { Denosumab } \\
(n=21,154)\end{array}$ & $\begin{array}{l}\text { Ibandronate } \\
(n=20,472)\end{array}$ & $\begin{array}{l}\text { Zoledronic acid } \\
(n=3966)\end{array}$ & $P$ value \\
\hline Age $\leq 60$ years, $\%$ & 7.1 & 8.1 & 11.9 & $<0.001$ \\
\hline Age $61-70$ years, $\%$ & 18.9 & 20.2 & 21.4 & $<0.001$ \\
\hline Age $>70$ years, $\%$ & 74.1 & 71.7 & 66.7 & $<0.001$ \\
\hline \multicolumn{5}{|c|}{ Specialty of doctor initiating therapy, $\%$} \\
\hline Orthopedic surgeon & 59.9 & 51.5 & 51.4 & $<0.001$ \\
\hline Internist & 33.5 & 42.8 & 37.4 & $<0.001$ \\
\hline Other & 6.5 & 5.7 & 11.1 & $<0.001$ \\
\hline \multicolumn{5}{|c|}{ Health insurance company, $\%$} \\
\hline $\mathrm{AOK}$ & 41.6 & 43.5 & 43.6 & $<0.001$ \\
\hline BKK & 9.2 & 8.1 & 7.8 & $<0.001$ \\
\hline DAK & 13.8 & 13.9 & 14.8 & 0.247 \\
\hline TK & 5.2 & 5.3 & 5.2 & 0.953 \\
\hline IKK & 3.4 & 3.6 & 4.1 & 0.073 \\
\hline Barmer GEK & 15.9 & 15.5 & 14.2 & 0.024 \\
\hline Other & 10.9 & 10.2 & 10.4 & 0.045 \\
\hline \multicolumn{5}{|c|}{ Prescription in the 12 months preceding the index date, $\%$} \\
\hline Oral bisphosphonates ${ }^{\mathrm{a}}$ & 22.9 & 26.6 & 20.8 & $<0.001$ \\
\hline Calcium $^{\mathrm{b}}$ & 36.6 & 34.7 & 36.3 & $<0.001$ \\
\hline Vitamin $D^{c}$ & 19.4 & 14.5 & 13.9 & $<0.001$ \\
\hline Hormone therapy ${ }^{\mathrm{d}}$ & 5.2 & 4.6 & 5.3 & 0.001 \\
\hline Pain medication ${ }^{\mathrm{e}}$ & 65.6 & 66.1 & 66.2 & 0.533 \\
\hline
\end{tabular}

$P$ values were calculated for denosumab versus pooled i.v. bisphosphonate data

ATC Anatomical Therapeutic Chemical, i.v. intravenous

${ }^{\mathrm{a}}$ ATC class: M05B3

${ }^{\mathrm{b}}$ ATC class: A12A

${ }^{\mathrm{c}} \mathrm{ATC}$ class: $\mathrm{A} 11 \mathrm{C} 2$ or $\mathrm{A} 11 \mathrm{C} 3$

${ }^{\mathrm{d}}$ ATC class: G03

e ATC class: N02 or M01A 
denosumab and oral bisphosphonates was also seen in the sensitivity analyses using grace periods of 30, 90, and 120 days (Table 3). Persistence rates for oral bisphosphonates using these alternative grace periods were consistently lowest for ibandronate $(7.3,21.2$, and $25.1 \%$ ) and highest for risedronate $(10.2,22.6$, and $26.9 \%)$ after 2 years of treatment (Table 3 ).

\section{Cox regression analysis}

The multivariate HRs from the Cox regression model are presented in Tables 4 and 5. Compared with patients receiving denosumab, those receiving i.v. ibandronate or i.v. zoledronic acid had a significantly higher risk of discontinuing treatment $(\mathrm{HR}=1.65$ and 1.28 , respectively; both $P<0.001$; Table 4$)$.
Patients treated with oral bisphosphonates showed an approximately twofold increased risk of treatment discontinuation compared with those receiving denosumab $(\mathrm{HR}=2.02$ for oral alendronate, 2.02 for oral ibandronate, and 1.96 for oral risedronate; all $P<0.0001$; Table 5).

Patients older than 60 years were significantly less likely to discontinue osteoporosis treatment than those aged 60 years or younger (Tables 4 and 5). Patients treated by specialists other than orthopedic surgeons and internists had a significantly higher risk of discontinuation than those who obtained their prescriptions from internists (Tables 4 and 5). However, these data should be interpreted with caution as the number of patients treated by other specialists was very low (Tables 1 and 2). The use of other osteoporosis treatments before the index date, such as oral bisphosphonates, calcium, or vitamin D, was

Table 2 Baseline characteristics of study patients: denosumab versus oral bisphosphonates

\begin{tabular}{|c|c|c|c|c|c|}
\hline Variable & $\begin{array}{l}\text { Denosumab } \\
(n=21,154)\end{array}$ & $\begin{array}{l}\text { Alendronate } 70 \mathrm{mg} \\
(n=90,077)\end{array}$ & $\begin{array}{l}\text { Ibandronate } \\
150 \mathrm{mg}(n=6235)\end{array}$ & $\begin{array}{l}\text { Risedronate } \\
35 \mathrm{mg}(n=18,089)\end{array}$ & $P$ value \\
\hline Age $\leq 60$ years, $\%$ & 7.1 & 9.9 & 9.8 & 8.7 & $<0.001$ \\
\hline Age $61-70$ years, $\%$ & 18.9 & 19.3 & 22.0 & 19.7 & $<0.001$ \\
\hline Age $>70$ years, $\%$ & 74.1 & 70.9 & 68.2 & 71.6 & $<0.001$ \\
\hline \multicolumn{6}{|c|}{$\begin{array}{l}\text { Specialty of doctor initiating } \\
\text { therapy, } \%\end{array}$} \\
\hline Orthopedic surgeon & 59.9 & 38.1 & 42.9 & 48.6 & $<0.001$ \\
\hline Internist & 33.5 & 56.9 & 49.4 & 46.5 & $<0.001$ \\
\hline Other & 6.5 & 5.0 & 7.7 & 4.9 & $<0.001$ \\
\hline \multicolumn{6}{|l|}{$\begin{array}{l}\text { Health insurance } \\
\text { company, \% }\end{array}$} \\
\hline AOK & 41.6 & 47.1 & 44.8 & 48.1 & $<0.001$ \\
\hline BKK & 9.2 & 9.3 & 7.9 & 8.0 & $<0.001$ \\
\hline DAK & 13.8 & 11.9 & 12.3 & 11.4 & $<0.001$ \\
\hline TK & 5.2 & 4.5 & 5.8 & 4.3 & $<0.001$ \\
\hline IKK & 3.4 & 3.4 & 4.2 & 3.5 & 0.013 \\
\hline Barmer GEK & 15.9 & 12.8 & 15.2 & 13.9 & $<0.001$ \\
\hline Other & 10.9 & 11.0 & 9.8 & 10.8 & 0.0365 \\
\hline \multicolumn{6}{|c|}{$\begin{array}{l}\text { Prescription in the } 12 \text { months } \\
\text { preceding the index date, \% }\end{array}$} \\
\hline Oral bisphosphonates ${ }^{\mathrm{a}}$ & 22.9 & 4.2 & 16.9 & 11.7 & $<0.001$ \\
\hline Calcium ${ }^{\mathrm{b}}$ & 36.6 & 31.3 & 33.2 & 40.9 & $<0.001$ \\
\hline Vitamin $\mathrm{D}^{\mathrm{c}}$ & 19.4 & 10.4 & 12.1 & 13.8 & $<0.001$ \\
\hline Hormone therapy ${ }^{\mathrm{d}}$ & 5.2 & 3.6 & 5.0 & 4.2 & $<0.001$ \\
\hline Pain medication ${ }^{\mathrm{e}}$ & 65.6 & 70.7 & 66.1 & 67.3 & $<0.001$ \\
\hline
\end{tabular}

$P$ values were calculated for denosumab versus pooled oral bisphosphonate data

ATC Anatomical Therapeutic Chemical

${ }^{\mathrm{a}}$ ATC class: M05B3

${ }^{\mathrm{b}}$ ATC class: A12A

${ }^{\mathrm{c}} \mathrm{ATC}$ class: $\mathrm{A} 11 \mathrm{C} 2$ or $\mathrm{A} 11 \mathrm{C} 3$

${ }^{\mathrm{d}}$ ATC class: G03

${ }^{\mathrm{e}}$ ATC class: N02 or M01A 
Table 3 Persistence over 12 months and 2 years with denosumab and intravenous bisphosphonates in Germany

\begin{tabular}{lllll}
\hline & Main analysis & \multicolumn{2}{l}{ Sensitivity analyses } & \\
\cline { 3 - 5 } & $\begin{array}{l}\text { 60-day grace } \\
\text { period }\end{array}$ & $\begin{array}{l}\text { 30-day grace } \\
\text { period }\end{array}$ & $\begin{array}{l}\text { 90-day grace } \\
\text { period }\end{array}$ & $\begin{array}{l}\text { 120-day grace } \\
\text { period }\end{array}$ \\
\hline 12-month persistence & & & & \\
Denosumab, \% & 55.9 & 38.0 & 61.5 & 65.1 \\
i.v. ibandronate, \% & 42.9 & 31.1 & 48.2 & 54.4 \\
i.v. zoledronic acid, \% & 33.8 & 20.3 & 39.7 & 43.7 \\
Oral alendronate, \% & 30.1 & 21.5 & 35.6 & 39.7 \\
Oral ibandronate, \% & 30.1 & 18.4 & 35.0 & 39.4 \\
Oral risedronate, \% & 31.4 & 22.6 & 36.9 & 41.4 \\
2-year persistence & & & 46.3 & 50.6 \\
Denosumab, \% & 39.8 & 21.6 & 30.2 & 36.7 \\
i.v. ibandronate, \% & 24.8 & 15.0 & 29.5 & 34.1 \\
i.v. zoledronic acid, \% & 20.9 & 6.5 & 22.5 & 26.5 \\
Oral alendronate, \% & 17.3 & 9.7 & 21.2 & 25.1 \\
Oral ibandronate, \% & 16.7 & 7.3 & 22.6 & 26.9 \\
Oral risedronate, \% & 17.5 & 10.2 & & \\
\hline
\end{tabular}

i.v. intravenous

associated with a significantly decreased risk of treatment discontinuation. While patients receiving analgesics before the index date were significantly more likely to discontinue therapy than those who were not receiving pain medication, the effect was relatively small ( $\mathrm{HR}=1.08$ for i.v. bisphosphonate/ denosumab therapy and 1.02 for oral bisphosphonate/ denosumab therapy). Having health insurance with BKK, TK, IKK, or Barmer GEK was associated with a lower risk of treatment discontinuation than having insurance with AOK (Tables 4 and 5).

\section{Discussion}

To our knowledge, this is the first study to assess persistence rates simultaneously for oral and i.v. bisphosphonates and s.c. denosumab in a large, real-world population with 2 years of follow-up. Our data show that patients receiving i.v. bisphosphonates are significantly more likely to discontinue treatment than those receiving denosumab $(\mathrm{HR}=1.28$ for $\mathrm{zo}-$ ledronic acid and 1.65 for ibandronate, both $P<0.0001)$ and those receiving oral bisphosphonates are twice as likely to discontinue treatment than those receiving denosumab (HR $=1.96-2.02$, all $P<0.0001)$. Two-year persistence with denosumab (39.8\%) was 1.5-2 times higher than with either i.v. bisphosphonates (20.9-24.8\%) or oral bisphosphonates (16.7-17.5\%).

Reports on short-term persistence with denosumab have been published previously [18, 23-25]. Our study found 12month persistence with denosumab to be $55.9 \%$, which was lower than rates reported in three RCTs: $90.5 \%$ in the Denosumab Adherence Preference Satisfaction (DAPS) study, $94 \%$ in the Study of Transitioning from Alendronate to Denosumab (STAND), and $93 \%$ in the Determining Efficacy: Comparison of Initiating Denosumab versus Alendronate (DECIDE) study [24-26]. There is no clear basis suggesting that this reflects a general trend for poor persistence with medication in Germany compared with other countries; indeed, it has been suggested that adherence to osteoporosis treatment is generally higher in Europe than in North America [14]. The differences can be largely attributed to the different study designs. For example, in the DAPS study [24], persistence with denosumab was defined as receiving two injections and completing the treatment period within the study-defined time span. Moreover, the retrospective, non-interventional design of our study reflects real-world practice, whereas patients in RCTs are likely to show good medicationtaking behavior because of regular on-study visits to their physician and the study eligibility criteria, which exclude women who have previously received osteoporosis treatments (e.g., DAPS) or restrict the previous treatments permitted (e.g., STAND and DECIDE). In addition, in RCTs, both patients and physicians must actively agree to participate, which could lead to selection bias.

Of the different grace periods considered in our sensitivity analyses, the results of the analysis using a 120-day grace period (which resulted in a 12-month persistence rate of $65.1 \%$ for denosumab) were closest to, though still markedly lower than, the reported rates of 82 and 
Fig. 1 After 2 years of follow-up, persistence with denosumab was significantly higher than with intravenous (a) or oral (b) bisphosphonates. Graphs show Kaplan-Meier curves and $95 \%$ confidence intervals
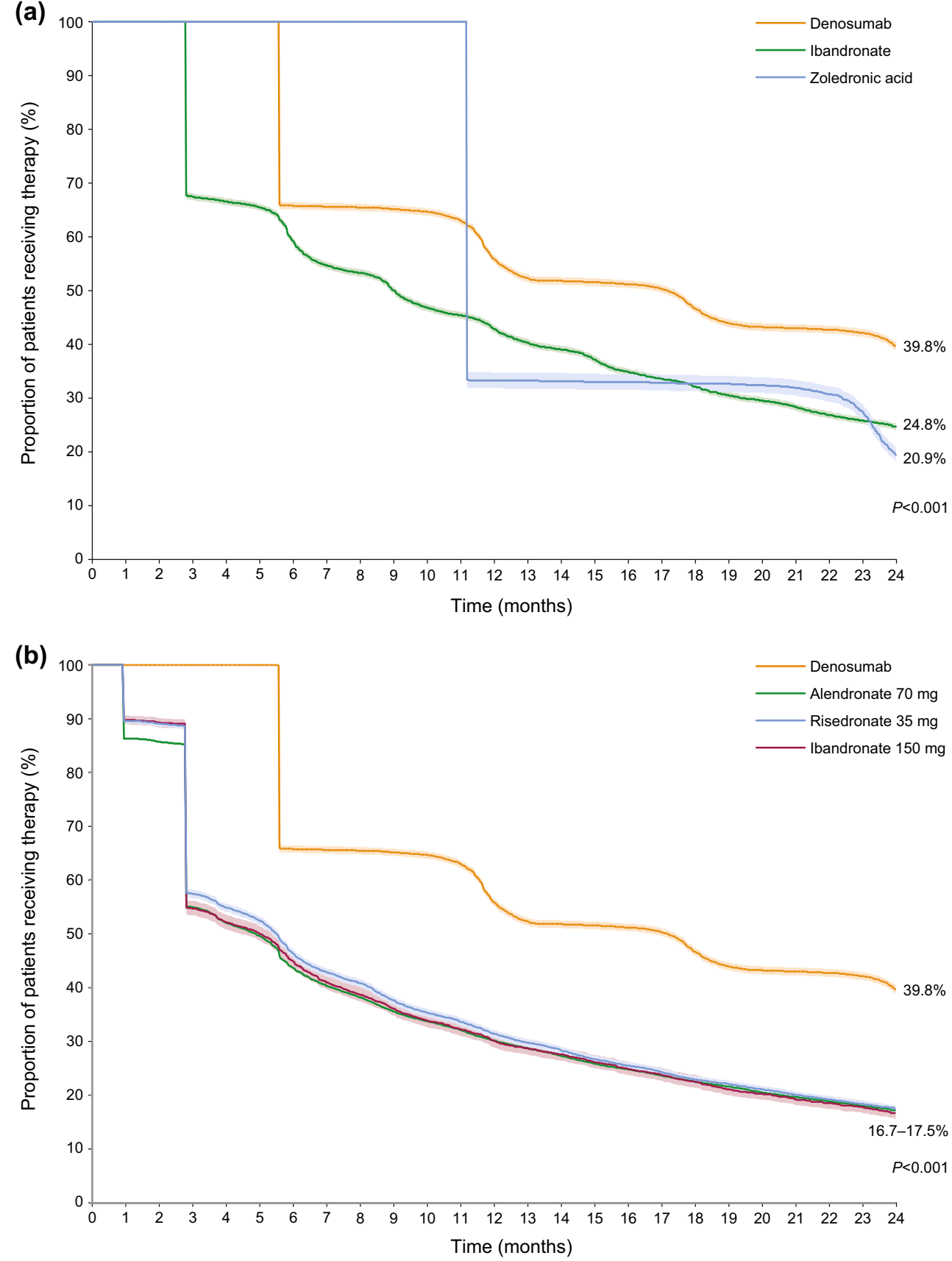

87.0-95.3\% in the prospective observational studies reported by Silverman et al. and Hadji et al., respectively, both of which used an 8 -week grace period [18, 19]. The inconsistency in reported persistence is probably a result of alternative endpoint definitions-both Silverman et al. and Hadji et al. calculated persistence relative to the previous injection, whereas we calculated it over the total study period. The inconsistency could also be due to the prospective nature of these studies, whereby patients were aware that their medication-taking behavior was being observed, which in turn could have increased on-study persistence [27].
Before this study, data on 2-year persistence with osteoporosis treatments were sparse. In the present analysis, 2-year persistence was higher for patients receiving denosumab than for those receiving i.v. or oral bisphosphonates. This result was seen consistently across different grace periods used in sensitivity analyses, indicating that the results are robust. Furthermore, the regression analysis, which was based on the 60-day grace period, found that the difference in persistence between denosumab and the other agents was statistically significant.

While 2-year persistence was relatively low with all agents studied, the rates are consistent with those from 
Table 4 Association of risk of discontinuation of denosumab or intravenous bisphosphonate treatment within 2 years with predefined outcome variables (Cox regression model analyses)

\begin{tabular}{lll}
\hline Variable & Hazard ratio (95 \% CI) & $P$ value \\
\hline Ibandronate $^{\mathrm{a}}$ & $1.65(1.61-1.69)$ & $<0.0001$ \\
Zoledronic acid $^{\mathrm{a}}$ & $1.28(1.23-1.33)$ & $<0.0001$ \\
Age 61-70 years $^{\mathrm{b}}$ & $0.95(0.92-0.98)$ & 0.0002 \\
Other doctor specialty (other than orthopedic surgeon or internist) $^{\mathrm{c}}$ & $1.14(1.09-1.20)$ & $<0.0001$ \\
Health insurance company & & \\
BKK $^{\mathrm{d}}$ & $0.93(0.89-0.96)$ & 0.0002 \\
$\mathrm{TK}^{\mathrm{d}}$ & $0.94(0.89-0.99)$ & 0.0111 \\
IKK $^{\mathrm{d}}$ & $0.89(0.84-0.95)$ & 0.0002 \\
Barmer GEK $^{\mathrm{d}}$ & $0.94(0.91-0.97)$ & $<0.0001$ \\
Previous osteoporosis medication & & $<0.0001$ \\
Oral bisphosphonates $^{\mathrm{e}}$ & $0.86(0.84-0.88)$ & $<0.0001$ \\
Calcium $^{\mathrm{f}}$ & $0.94(0.92-0.97)$ & $<0.0001$ \\
Previous pain medication $^{\mathrm{g}}$ & $1.08(1.06-1.11)$ & \\
\hline
\end{tabular}

Table shows only variables significantly associated with risk of discontinuation

ATC Anatomical Therapeutic Chemical, CI confidence interval

${ }^{\mathrm{a}}$ Reference group $=$ denosumab

${ }^{\mathrm{b}}$ Reference group $=$ age $\leq 60$ years

${ }^{\mathrm{c}}$ Reference group $=$ internist

${ }^{\mathrm{d}}$ Reference group $=$ AOK

${ }^{\mathrm{e}}$ Reference group $=$ no previous oral bisphosphonates (ATC class: M05B3)

${ }^{\mathrm{f}}$ Reference group $=$ no previous calcium (ATC class: A12A)

${ }^{\mathrm{g}}$ Reference group $=$ no previous pain medication (ATC class: N02 or M01A) other studies of persistence with bisphosphonates. In the GRAND study [9], 1- and 2-year persistence with oral bisphosphonates was 27.9 and $12.9 \%$, respectively. The authors of this study discussed the influences of individual factors on non-persistence and concluded that the main drivers of discontinuation are gastrointestinal side effects and difficulties in taking oral bisphosphonates (e.g., the need to take them on an empty stomach with water and then remain upright for at least $30 \mathrm{~min}$ [28]). In a Hungarian cohort study, 1- and 2-year persistence rates were lower for oral therapies than for parenteral therapies [15]. Furthermore, a study of osteoporosis treatment in France found that short dosing intervals appeared to have a negative effect on treatment compliance and persistence with oral bisphosphonates [29]. Similarly, data from prospective randomized trials have shown that patients prefer less frequent dosing, such as 6-monthly s.c. injections or 12-monthly i.v. infusions of denosumab and zoledronic acid, respectively, compared with once-weekly oral alendronate therapy [30, 31]. In addition, Palacios et al. [21] evaluated changes in treatment satisfaction among postmenopausal women who were non-adherent to daily or weekly bisphosphonates and who were transitioned to either a monthly oral bisphosphonate or denosumab; treatment satisfaction was greater in the denosumab cohort than in the monthly oral bisphosphonate cohort. Treatment satisfaction with osteoporosis agents appears to be a decisive parameter for adherence and persistence [32], which may explain the results seen in our study. It is also worth considering the relative longevity of the skeletal effects of bisphosphonates after treatment discontinuation compared with those of denosumab [33]. This reinforces the particular requirement for persistence with denosumab; recognition of this may influence the emphasis with which physicians communicate the importance of medication adherence to their patients.

Although data on longer-term persistence with i.v. bisphosphonates are lacking, we are able to compare the 12-month rates in our study (42.9 and $33.8 \%$ for i.v. ibandronate and zoledronic acid, respectively) with those seen in other studies of treatment persistence. For example, two studies of i.v. zoledronic acid in women with osteoporosis reported similar persistence rates of 36 and $68 \%$ after 12 months [34, 35]. Additionally, a population-based study using the IMS database in Germany demonstrated that 56.6 and $65.6 \%$ of the study population receiving i.v. ibandronate and zoledronic acid, respectively, were still on treatment after 12 months of follow-up [16]. The findings from our 
Table 5 Association of risk of discontinuation of denosumab or oral bisphosphonate treatment within 2 years with predefined outcome variables (Cox regression model analyses)

\begin{tabular}{|c|c|c|}
\hline Variable & Hazard ratio $(95 \% \mathrm{CI})$ & $P$ value \\
\hline Alendronate $70 \mathrm{mg}^{\mathrm{a}}$ & $2.02(1.98-2.06)$ & $<0.0001$ \\
\hline Ibandronate $150 \mathrm{mg}^{\mathrm{a}}$ & $2.02(1.95-2.09)$ & $<0.0001$ \\
\hline Risedronate $35 \mathrm{mg}^{\mathrm{a}}$ & $1.96(1.91-2.01)$ & $<0.0001$ \\
\hline \multicolumn{3}{|l|}{ Age } \\
\hline Age $61-70$ years ${ }^{\mathrm{b}}$ & $0.91(0.89-0.93)$ & $<0.0001$ \\
\hline Age $>70$ years $^{\mathrm{b}}$ & $0.89(0.88-0.91)$ & $<0.0001$ \\
\hline Other doctor specialty (other than orthopedic surgeon or internist) ${ }^{c}$ & $1.22(1.19-1.26)$ & $<0.0001$ \\
\hline \multicolumn{3}{|l|}{ Health insurance company } \\
\hline $\mathrm{BKK}^{\mathrm{d}}$ & $0.95(0.93-0.97)$ & $<0.0001$ \\
\hline $\mathrm{IKK}^{\mathrm{d}}$ & $0.88(0.85-0.91)$ & $<0.0001$ \\
\hline Barmer GEK ${ }^{\mathrm{d}}$ & $0.96(0.94-0.97)$ & $<0.0001$ \\
\hline \multicolumn{3}{|l|}{ Previous osteoporosis medication } \\
\hline Oral bisphosphonates ${ }^{\mathrm{e}}$ & $0.90(0.88-0.92)$ & $<0.0001$ \\
\hline Calcium $^{\mathrm{f}}$ & $0.93(0.92-0.95)$ & $<0.0001$ \\
\hline Vitamin $D^{g}$ & $0.96(0.95-0.98)$ & $<0.0001$ \\
\hline Previous pain medication ${ }^{\mathrm{h}}$ & $1.02(1.00-1.03)$ & 0.016 \\
\hline
\end{tabular}

Table shows only variables significantly associated with risk of discontinuation

ATC Anatomical Therapeutic Chemical, CI confidence interval

${ }^{\mathrm{a}}$ Reference group $=$ denosumab

${ }^{\mathrm{b}}$ Reference group $=$ age $\leq 60$ years

${ }^{\mathrm{c}}$ Reference group $=$ internist

${ }^{\mathrm{d}}$ Reference group $=\mathrm{AOK}$

${ }^{\mathrm{e}}$ Reference group $=$ no previous oral bisphosphonates (ATC class: M05B3)

${ }^{\mathrm{f}}$ Reference group $=$ no previous calcium (ATC class: A12A)

${ }^{\mathrm{g}}$ Reference group $=$ no previous vitamin D (ATC class: $\mathrm{A} 11 \mathrm{C} 2$ or A11C3)

${ }^{\mathrm{h}}$ Reference group $=$ no previous pain medication (ATC class: N02 or M01A) study suggest that there is also a high rate of discontinuation during the second year of treatment, with persistence rates after 2 years of treatment of 24.8 and $21.2 \%$ for i.v. ibandronate and i.v. zoledronic acid, respectively.

Several studies have found associations between poor persistence with osteoporosis treatment and fracture risk [9, 14, 36-39]; hence, the low rates of persistence seen in the current study are of concern, and it is important to gain a better understanding of how we can optimize medication-taking behavior. This, in turn, could allow us to maximize treatment effects, prevent fractures, and minimize healthcare costs [40].

Little is known about factors associated with treatment discontinuation over a 2-year period. We found that being over 60 years of age was associated with a lower risk of treatment discontinuation compared with younger individuals. This observation might be due to older patients having more severe disease than younger patients and therefore being more likely to be prescribed denosumab or i.v. bisphosphonates, which are associated with higher long-term persistence rates than the oral bisphosphonates typically used as first-line treatment.
We also found that previous treatment with bisphosphonates, calcium, vitamin $\mathrm{D}$, or pain medication was associated with better persistence. This is in line with previously published studies of determinants of persistence with denosumab [17, $18]$ and could reflect a tendency for women who have previously received osteoporosis treatment to be better informed about their disease and to receive more information from their prescriber than treatment-naïve women [17]. In this study, patients insured through AOK demonstrated poorer persistence than patients insured through BKK, TK, IKK, or Barmer GEK. AOK is the largest statutory health insurance provider in Germany, so the low persistence in patients in this group is of concern. It may, however, reflect a higher proportion of patients with low income, or who are unemployed or retired, among the AOK population compared with other insurance groups. Indeed, a previous study found that income level was significantly associated with persistence in patients with osteoporosis [41].

Certain limitations warrant consideration. The retrospective nature of the study, as well as the limited number of factors potentially associated with persistence for which data are included in the database, prevents us from 
identifying further risk factors for poor persistence. Also, associations with possible confounders, such as severity of disease, bone mineral density, bone turnover markers, and prevalent fractures, could not be assessed. Physicians may vary in the way they classify new versus continued use of osteoporosis treatments. In particular, re-initiation of previous treatment may not be coded consistently. The data may also be affected by confounding by indication, because patients who receive injectable agents are more likely to have severe disease and to have received previous therapy than those receiving oral bisphosphonates. Individuals who discontinued their original therapy and started another drug within 60 days were included in the drug cohort in which they maintained the longest duration of persistence, which may have led to an overestimation of persistence for the agents used as the initial therapy in such cases. Analysis of persistence may also have been confounded by instances of extended prescription intervals, undetected by the maximum grace period of 120 days. For example, data demonstrating that the benefits of a single i.v. dose of zoledronic acid endure for more than a year may underlie a trend for biennial dosing in some regions [42]. This is not recognized practice in Germany, however, and is not advocated by treatment guidelines; thus, it is unlikely to have affected our findings significantly [43]. Finally, this analysis may have been complemented by the availability of additional data that were not analyzed, such as further details on previous fractures, osteoporosis treatment history, and comorbidity profiles of patients, as well as a more comprehensive breakdown of physician specialty. It would be of interest to examine the effects of these variables in future studies.

Our study has several strengths. Our analysis used realworld data from physicians, capturing over $60 \%$ of prescriptions for osteoporosis treatment in women and providing insights into treatment persistence in a real-world clinical practice setting. Furthermore, we assessed treatment persistence using four different grace periods and showed that shorter gaps (e.g., 30 days) might underestimate persistence whereas longer gaps might overestimate persistence. Finally, unlike previous studies, we compared all available bisphosphonate treatment regimens, as well as denosumab, for a long duration (>12 months) of follow-up.

\section{Conclusion}

Two-year persistence was 1.5-2 times higher with denosumab than with bisphosphonates, and the risk of discontinuing treatment was significantly lower with denosumab than with bisphosphonates, even if patients were receiving i.v. ibandronate or i.v. zoledronic acid. Although this improvement has value, further increases in persistence with antiresorptive agents in patients with osteoporosis are needed. Greater understanding of the factors associated with poor persistence is required in order to improve medication-taking behavior in patients at high risk of treatment discontinuation and to maximize fracture risk reduction.

Acknowledgments This study was supported by Amgen GmbH. Medical writing support was provided by Claire Desborough of Amgen Europe $(\mathrm{GmbH})$ and Kim Allcott PhD of Oxford PharmaGenesis, Oxford, UK, funded by Amgen (Europe) GmbH.

\section{Compliance with Ethical Standards}

Conflicts of interest This study was supported by Amgen GmbH. MS, MI, and TS are Amgen employees and shareholders. EP was an Amgen employee and shareholder at the time of conducting this study and manuscript preparation. $\mathrm{PH}$ has received honoraria, unrestricted educational grants, and research funding from Amgen, AstraZeneca, Eli Lilly, GlaxoSmithKline, Novartis, Pfizer, Procter \& Gamble, and Roche. IK has received honoraria, unrestricted educational grants, and funding from Amgen. LH has received honoraria, unrestricted educational grants, and research funding from Amgen, Eli Lilly, and Novartis. CN has received honoraria, unrestricted educational grants, and research funding from Amgen, Eli Lilly, Merck Sharp \& Dohme, and UCB Pharma. PHK received honoraria, unrestricted grants, and research funding from Amgen, Eli Lilly, GlaxoSmithKline, Ipsen, Novo Nordisk, Novartis, Pfizer, Procter \& Gamble, Roche, and Sanofi Aventis. HS has received honoraria and unrestricted educational grants from Prüfungseinrichtungen BadenWürttemberg, KV Baden-Württemberg, AOK, BEK, DAK, TKK, BKK's, IKK, LKK, BK, Heilfürsorge, BG, Ärztekammer BadenWürttemberg, Patienten, Diverse Kliniken, Amgen, Anwerina, Astra, Daichi, Glaxo, Grünenthal, Janssen, Kade, Lilly, Medi, Medtronic, Omnia-Med, Orion, Medical Tribune, MSD, Mundipharma, Novartis, Nycomed, Pfizer, Procter \& Gamble, Roche, Servier, and Teva. AAK has received honoraria, unrestricted educational grants, and research funding from Amgen, Baxter, Biomet, Boehringer Ingelheim, Dfine, Eli Lilly, GlaxoSmithKline, Novartis, Pfizer, Procter \& Gamble, and Roche. FT has received honorarium by Lilly, Amgen, Boehringer, and Takeda.

Open Access This article is distributed under the terms of the Creative Commons Attribution-NonCommercial 4.0 International License (http:// creativecommons.org/licenses/by-nc/4.0/), which permits any noncommercial use, distribution, and reproduction in any medium, provided you give appropriate credit to the original author(s) and the source, provide a link to the Creative Commons license, and indicate if changes were made.

\section{References}

1. Johnell O, Kanis JA (2006) An estimate of the worldwide prevalence and disability associated with osteoporotic fractures. Osteoporos Int 17:1726-1733

2. Szulc P, Bouxsein ML Vertebral Fracture Initiative: PART I Osteoporosis and related fractures: an under-diagnosed and undertreated public health issue. http://www.iofbonehealth.org/sites/ default/files/PDFs/Vertebral\%20Fracture\%20Initiative/IOF VFIPart_I-Manuscript.pdf. Accessed January 2016

3. Hadji P, Klein S, Gothe H, Haussler B, Kless T, Schmidt T, Steinle T, Verheyen F, Linder R (2013) The epidemiology of 
osteoporosis-Bone Evaluation Study (BEST): an analysis of routine health insurance data. Dtsch Arztebl Int 110:52-57

4. Ettinger B (2005) Bisphosphonates: providing strength to a significant class. Manag Care 14:24-28

5. Kennel KA, Drake MT (2009) Adverse effects of bisphosphonates: implications for osteoporosis management. Mayo Clin Proc 84: 632-637, quiz 638

6. Amgen (2015) Prolia (denosumab) summary of product characteristics. http://www.ema.europa.eu/docs/en_GB/document_library/ EPAR - Product Information/human/001120/WC500093526. pdf. Accessed January 2016

7. Kostenuik PJ, Nguyen HQ, McCabe J, Warmington KS, Kurahara C, Sun N, Chen C, Li L, Cattley RC, Van G et al (2009) Denosumab, a fully human monoclonal antibody to RANKL, inhibits bone resorption and increases BMD in knock-in mice that express chimeric (murine/human) RANKL. J Bone Miner Res 24: 182-195

8. Hofbauer LC, Schoppet M (2004) Clinical implications of the osteoprotegerin/RANKL/RANK system for bone and vascular diseases. JAMA 292:490-495

9. Hadji P, Claus V, Ziller V, Intorcia M, Kostev K, Steinle T (2012) GRAND: the German retrospective cohort analysis on compliance and persistence and the associated risk of fractures in osteoporotic women treated with oral bisphosphonates. Osteoporos Int 23:223231

10. Hoer A, Seidlitz C, Gothe H, Schiffhorst G, Olson M, Hadji P, Haussler B (2009) Influence on persistence and adherence with oral bisphosphonates on fracture rates in osteoporosis. Patient Prefer Adh 3:25-30

11. Gold DT, Martin BC, Frytak JR, Amonkar MM, Cosman F (2007) A claims database analysis of persistence with alendronate therapy and fracture risk in post-menopausal women with osteoporosis. Curr Med Res Opin 23:585-594

12. Cotte FE, Mercier F, De Pouvourville G (2008) Relationship between compliance and persistence with osteoporosis medications and fracture risk in primary health care in France: a retrospective case-control analysis. Clin Ther 30:2410-2422

13. Majumdar SR, Johnson JA, Lier DA, Russell AS, Hanley DA, Blitz S, Steiner IP, Maksymowych WP, Morrish DW, Holroyd BR et al (2007) Persistence, reproducibility, and cost-effectiveness of an intervention to improve the quality of osteoporosis care after a fracture of the wrist: results of a controlled trial. Osteoporos Int 18:261270

14. Siris ES, Selby PL, Saag KG, Borgstrom F, Herings RM, Silverman SL (2009) Impact of osteoporosis treatment adherence on fracture rates in North America and Europe. Am J Med 122:S3-13

15. Lakatos P, Takacs I, Marton I, Toth E, Zoltan C, Lang Z, Psachoulia E, Intorcia M (2016) A retrospective longitudinal database study of persistence and compliance with treatment of osteoporosis in Hungary. Calcif Tissue Int 98:215-225

16. Ziller V, Kostev K, Kyvernitakis I, Boeckhoff J, Hadji P (2012) Persistence and compliance of medications used in the treatment of osteoporosis - analysis using a large scale, representative, longitudinal German database. Int J Clin Pharmacol Ther 50:315-322

17. Karlsson L, Lundkvist J, Psachoulia E, Intorcia M, Strom O (2015) Persistence with denosumab and persistence with oral bisphosphonates for the treatment of postmenopausal osteoporosis: a retrospective, observational study, and a meta-analysis. Osteoporos Int 26:2401-2411

18. Silverman SL, Siris E, Kendler DL, Belazi D, Brown JP, Gold DT, Lewiecki EM, Papaioannou A, Simonelli C, Ferreira I et al (2015) Persistence at 12 months with denosumab in postmenopausal women with osteoporosis: interim results from a prospective observational study. Osteoporos Int 26:361-372

19. Hadji P, Papaioannou N, Gielen E, Feudjo Tepie M, Zhang E, Frieling I, Geusens P, Makras P, Resch H, Moller G et al (2015) Persistence, adherence, and medication-taking behavior in women with postmenopausal osteoporosis receiving denosumab in routine practice in Germany, Austria, Greece, and Belgium: 12-month results from a European non-interventional study. Osteoporos Int 26:2479-2489

20. Schmid T, Hadji P, Eisen C, Intorcia M, Psachoulia P (2014) GRAND 3-the German retrospective cohort analysis on nonadherence in osteoporotic patients: persistence-analysis of female patients treated with denosumab. Osteoporos Int 25:264

21. Palacios S, Agodoa I, Bonnick S, Van den Bergh JP, Ferreira I, Ho PR, Brown JP (2015) Treatment satisfaction in postmenopausal women suboptimally adherent to bisphosphonates who transitioned to denosumab compared with risedronate or ibandronate. J Clin Endocrinol Metab 100:E487-492

22. IMS Health (2015) Longitudinal prescription data. http://www. imshealth.com/vgn-ext-templating/v/index.jsp?vgnextoid= 50945b02711b7410VgnVCM10000076192ca2RCRD\& vgnextchannel $=50945 \mathrm{~b} 02711 \mathrm{~b} 7410 \mathrm{VgnVCM} 10000076192$ ca2RCRD\&vgnextfmt=default. Accessed 2015 August

23. Kendler DL, McClung MR, Freemantle N, Lillestol M, Moffett AH, Borenstein J, Satram-Hoang S, Yang YC, Kaur P, Macarios D et al (2011) Adherence, preference, and satisfaction of postmenopausal women taking denosumab or alendronate. Osteoporos Int 22:1725-1735

24. Freemantle N, Satram-Hoang S, Tang ET, Kaur P, Macarios D, Siddhanti S, Borenstein J, Kendler DL, Investigators D (2012) Final results of the DAPS (Denosumab Adherence Preference Satisfaction) study: a 24-month, randomized, crossover comparison with alendronate in postmenopausal women. Osteoporos Int 23: 317-326

25. Brown JP, Prince RL, Deal C, Recker RR, Kiel DP, de Gregorio LH, Hadji P, Hofbauer LC, Alvaro-Gracia JM, Wang H et al (2009) Comparison of the effect of denosumab and alendronate on BMD and biochemical markers of bone turnover in postmenopausal women with low bone mass: a randomized, blinded, phase 3 trial. J Bone Miner Res 24:153-161

26. Kendler DL, Roux C, Benhamou CL, Brown JP, Lillestol M, Siddhanti S, Man HS, San Martin J, Bone HG (2010) Effects of denosumab on bone mineral density and bone turnover in postmenopausal women transitioning from alendronate therapy. J Bone Miner Res 25:72-81

27. McCarney R, Warner J, Iliffe S, van Haselen R, Griffin M, Fisher P (2007) The Hawthorne Effect: a randomised, controlled trial. BMC Med Res Methodol 7:30

28. Sambrook P, Cooper C (2006) Osteoporosis. Lancet 367:2010 2018

29. Huas D, Debiais F, Blotman F, Cortet B, Mercier F, Rousseaux C, Berger V, Gaudin AF, Cotte FE (2010) Compliance and treatment satisfaction of post menopausal women treated for osteoporosis. Compliance with osteoporosis treatment. BMC Womens Health 10:26

30. McClung M, Recker R, Miller P, Fiske D, Minkoff J, Kriegman A, Zhou W, Adera M, Davis J (2007) Intravenous zoledronic acid $5 \mathrm{mg}$ in the treatment of postmenopausal women with low bone density previously treated with alendronate. Bone 41:122-128

31. Kendler DL, Bessette L, Hill CD, Gold DT, Horne R, Varon SF, Borenstein J, Wang H, Man HS, Wagman RB et al (2010) Preference and satisfaction with a 6-month subcutaneous injection versus a weekly tablet for treatment of low bone mass. Osteoporos Int 21:837-846

32. Barrett-Connor E, Wade SW, Do TP, Satram-Hoang S, Stewart R, Gao G, Macarios D (2012) Treatment satisfaction and persistence among postmenopausal women on osteoporosis medications: 12month results from POSSIBLE US. Osteoporos Int 23:733-741

33. Adami S, Idolazzi L, Fracassi E, Gatti D, Rossini M (2013) Osteoporosis treatment: when to discontinue and when to re-start. Bone Res 1:323-335 
34. Lee YK, Nho JH, Ha YC, Koo KH (2012) Persistence with intravenous zoledronate in elderly patients with osteoporosis. Osteoporos Int 23:2329-2333

35. Curtis JR, Yun H, Matthews R, Saag KG, Delzell E (2012) Adherence with intravenous zoledronate and intravenous ibandronate in the United States Medicare population. Arthritis Care Res (Hoboken) 64:1054-1060

36. Halpern R, Becker L, Iqbal SU, Kazis LE, Macarios D, Badamgarav E (2011) The association of adherence to osteoporosis therapies with fracture, all-cause medical costs, and all-cause hospitalizations: a retrospective claims analysis of female health plan enrollees with osteoporosis. J Manag Care Pharm 17:25-39

37. Ross S, Samuels E, Gairy K, Iqbal S, Badamgarav E, Siris E (2011) A meta-analysis of osteoporotic fracture risk with medication nonadherence. Value Health 14:571-581

38. Siris ES, Harris ST, Rosen CJ, Barr CE, Arvesen JN, Abbott TA, Silverman S (2006) Adherence to bisphosphonate therapy and fracture rates in osteoporotic women: relationship to vertebral and nonvertebral fractures from 2 US claims databases. Mayo Clin Proc 81:1013-1022
39. Wade SW, Curtis JR, Yu J, White J, Stolshek BS, Merinar C, Balasubramanian A, Kallich JD, Adams JL, Viswanathan HN (2012) Medication adherence and fracture risk among patients on bisphosphonate therapy in a large United States health plan. Bone 50:870-875

40. Jonsson B, Strom O, Eisman JA, Papaioannou A, Siris ES, Tosteson A, Kanis JA (2011) Cost-effectiveness of denosumab for the treatment of postmenopausal osteoporosis. Osteoporos Int 22:967-982

41. Rolnick SJ, Pawloski PA, Hedblom BD, Asche SE, Bruzek RJ (2013) Patient characteristics associated with medication adherence. Clin Med Res 11:54-65

42. Reid IR, Black DM, Eastell R, Bucci-Rechtweg C, Su G, Hue TF, Mesenbrink P, Lyles KW, Boonen S, Trial HPF et al (2013) Reduction in the risk of clinical fractures after a single dose of zoledronic Acid 5 milligrams. J Clin Endocrinol Metab 98:557-563

43. Dachverband Osteologie (2011) DVO Guideline 2009 for prevention, diagnosis and therapy of osteoporosis in adults. Osteologie 20: $55-74$ 